\title{
A PROGÊNIE DO ENSINO SUPERIOR NO INTERIOR DO ESTADO DO PARANÁ: A FACULDADE DE FARMÁCIA E ODONTOLOGIA DE PONTA GROSSA
}

\author{
Antonio Carlos Frasson ${ }^{1}$ \\ Ademir Gebara ${ }^{2}$ \\ Luiz Alberto Pilatti ${ }^{3}$
}

\section{RESUMO}

O Ensino Superior em Ponta Grossa surge em meados da década de 30, quando as universidades brasileiras deixavam de ter um caráter efêmero. No entanto, esse caráter tardio não produziu um roteiro diferente do ocorrido na quase totalidade das universidades brasileiras do período. A primeira faculdade criada e implantada em Ponta Grossa, que foi também a primeira do interior do Estado, a Faculdade de Farmácia e Odontologia de Ponta Grossa, não logrou êxito. Nenhuma outra faculdade foi implantada na cidade até o final da década de 40. O presente texto tem por objetivo discutir como ocorreu essa implantação e os motivos do fracasso da instituição. Deve-se destacar que praticamente a totalidade dos trabalhos que têm como objeto o Ensino Superior em Ponta Grossa desconsideram esse momento "inicial".

Palavras-Chave: Ensino Superior; História da Educação Superior; Faculdade de Farmácia e Odontologia de Ponta Grossa.

\section{THE PROGENY OF THE HIGHER EDUCATION INSIDE THE STATE OF PARANÁ: THE UNIVERSITY OF PHARMACY AND DENTISTRY OF PONTA GROSSA}

\begin{abstract}
The Higher education in Ponta Grossa starts in the middle of the 30's, when the Brazilian universities stopped having an ephemeral character. However, the character of being late did not take a course different from the one taken by almost all the Brazilian universities of the period. The first Faculty created and implanted in Ponta Grossa, which was also the first one of the interior of the State, the Faculty of Pharmacy and Dentistry of Ponta Grossa, did not achieve success. No other Graduation course was implanted in the city until the end of the 40's. The present text aims to discuss how that implantation occurred and the reasons for the failure of the institution. It should be highlighted that the majority of the studies that have as an object the Higher Education in Ponta Grossa, don'take that "initial" moment into consideration.
\end{abstract}

Keywords: Higher Education; History of the Higher Education; Faculty of Pharmacy and Dentistry of Ponta Grossa.

\section{INTRODUÇÃO}

O Ensino Superior em Ponta Grossa surge em meados da década de 30, quando as universidades brasileiras deixavam de ter um caráter efêmero. Esse surgimento tardio deve-se, em parte, à recentidade do próprio Estado do Paraná. No entanto, isso não produziu um roteiro diferente do ocorrido na quase totalidade das universidades brasileiras.

A primeira faculdade criada e implantada em Ponta Grossa, que foi também a primeira do interior do Estado, a Faculdade de Farmácia e Odontologia de Ponta Grossa, não logrou êxito. Nenhuma outra foi implantada na cidade até o final da década de 40 . 
Com efeito, os limites temporais para o exame da progênie do ensino superior no interior do Estado do Paraná são de meados da década de 30 até o final da década de 40.

Antes de examinarmos como ocorreu essa implantação e os motivos do fracasso da instituição implantada, devemos destacar que praticamente a totalidade dos trabalhos que têm como objeto o Ensino Superior em Ponta Grossa desconsideram ou tratam superficialmente esse momento "inicial", uma vez que pouquíssimos os registros e os documentos oficiais sobre esse momento da história do ensino superior ponta-grossense ${ }^{5}$. Avançar, então, por essa via revelou-se improdutiva e incipiente.

Assim, uma nova condução se fez necessária a fim de que se construísse um corpus documental adequado. Primeiramente, a utilização de matéria jornalística representativas do período em questão. Para tal, revelaram-se significativas as edições da época do matutino Diário dos Campos. Um segundo recurso foi a utilização de entrevistas - o relato oral - considerada como uma importante estratégia de informação ${ }^{6}$.

Dentro desses limites, o presente estudo discute a implantação da Faculdade de Farmácia e Odontologia de Ponta Grossa e os motivos de seu fracasso.

\section{A FACULDADE DE FARMÁCIA E ODONTOLOGIA DE PONTA GROSSA}

A implantação da primeira faculdade em Ponta Grossa ocorreu no primeiro governo de Getulio Vargas. Período conhecido como Brasil - Novo (1930 a 1937), que foi marcado pelo autoritarismo e o populismo em que o desenvolvimento econômico, o nacionalismo, o controle sobre os trabalhadores e sobre os sindicatos, o planejamento estatal, a legislação social, os investimentos públicos e, sobretudo, pelo papel atribuído ao Estado como agente econômico foram marcas indeléveis do período.

Silva $(1999$, p.149) ao discorrer sobre este período da história brasileira destaca que o sistema econômico imposto por Vargas conduzia para o progresso face à criação de "ministérios específicos para a indústria, comércio, trabalho, educação e saúde. [...] a participação do Estado na economia está impregnada de um caráter planificador que, muitas vezes, evolui para a atuação empresarial”.

Além deste progresso econômico foi também, um período de expansão quantitativa do ensino superior no Brasil. A expansão ocorrida teve como marco a reforma Francisco Campos efetuada em 1931, a qual deu nova conformação ao ensino superior brasileiro, que se caracterizou, principalmente, pelas atividades de ensino, o que, de certa forma, colocava as universidades num patamar menor. Boaventura (1989, p. 110) analisando esta situação aponta que "não se fizeram à Universidade grandes exigências de esforço de pesquisa ou domínio da tecnologia existente [...]".

Neste contexto, o Estado do Paraná passa a viver um momento caracterizado por uma surpreendente expansão econômica e populacional, o que impele os seus governantes a uma busca de identidade de seus habitantes (IPARDES, 1989).

Padis (1981, p. 195) destaca este momento ao relatar "o rápido aumento demográfico e o povoamento de grande parte do território exigiam do Estado uma estrutura administrativa ágil e largamente dotada de recursos". Dessa forma passa a ocorrer uma nova fase política, econômica, social e cultural.

E foi assim que Ponta Grossa, então segunda cidade do Estado, ganhou destaque como um pólo de desenvolvimento sócio-econômico, constituindo-se num significativo centro comercial e econômico. Tradicional por fazer parte do "caminho das tropas"7, a cidade transforma-se rapidamente para constituir o que é, ainda hoje, um dos mais significativos entroncamentos rodoferroviários do País. $\mathrm{Na}$ prática, este processo 
transformou a cidade num pólo regional. Pessoas oriundas de outros centros chegaram à cidade em busca de novas oportunidades.

Nesse cenário, um grupo de ponta-grossenses ${ }^{8}$ avistam a necessidade de criação de um estabelecimento de ensino superior que viesse a preencher a carência de mão-de-obra qualificada exigida pelos novos tempos.

Além disso, os filhos da classe média que não tinham oportunidade de se deslocarem da cidade e da região para centros maiores, como Curitiba, São Paulo ou Rio de Janeiro, poderiam realizar seus estudos de nível superior na própria região. O diploma universitário era, ao mesmo tempo, uma possibilidade de ascensão social para as classes intermediárias e um mecanismo desenvolvimentista para uma cidade emergente em nítido processo de urbanização. Assim é descrito no Jornal Diário dos Campos (27 de abril de 1936, p. 27).

[...] Ponta Grossa vinha reclamando, desde algum tempo, a criação de uma casa de ensino, onde os alumnos que completassem o curso gymnasial e desejassem abraçar a profissão de pharmaceutico ou dentista, os quaes, anualmente tinham que transferir-se para Curityba ou São Paulo, e alli entregar-se ao prosseguimento dos estudos num curso demorado, e além do mais dispendioso, não só pelo elevado das mensalidades com, ainda, pelo custo de hospedagem e extraordinários de que aqui naturalmente ficariam dispensados porque estariam em suas próprias casas.

O caminho para a abertura da primeira unidade de ensino superior no interior do estado foi principalmente o político. A criação da faculdade ocorreu por pressões de diferentes segmentos sociais, entre os quais se destaca a imprensa escrita, através do jornal Diário dos Campos, no caso de Ponta Grossa. O grande interlocutor dessa "elite", junto ao governo do estado, foi o Prefeito Albary Guimarães. Outras figuras do cenário político também se uniram ao movimento existente e apresentaram ao Governador Manoel Ribas os anseios da comunidade ponta-grossense.

A notícia do atendimento do pedido veio pelo jornal Diário dos Campos (12 de dezembro de 1936, p. 1). O teor da reportagem que apresenta a notícia é o seguinte:

O proprietário de um dos principaes estabelecimentos farmacêuticos daqui nos informou ter sabido, através de uma conversação que manteve com um certo deputado estadual que o Sr. Manoel Ribas, preclaro governador do Estado, pretende findar em Ponta Grossa, uma Escola de Farmácia e Odontologia, semelhante á que existe em Santa Maria no Rio Grande do Sul. Trata-se, como é fácil de prever, de uma iniciativa que virá beneficiar grandemente Ponta Grossa, pois o estabelecimento de ensino em apreço, além de vir enriquecer o nosso patrimônio educacional, proporcionará à sociedade sem grandes recursos da Princeza dos Campos e de todo o interior meios para com mais facilidade de que nas capitaes, obter as pergaminhas aquellas significantes.

No dia seguinte, o mesmo jornal apresenta a posição do Governador Manoel Ribas sobre a notícia vinculada. A manifestação do governador tem o seguinte tom conforme noticiado na data de 13 de dezembro de 1936 (p. 1): 
Na verdade, manifestei essa minha intenção pouco tempo depois que aqui cheguei. Uma escola de farmacia e odontologia em Ponta Grossa, vi logo, prestaria os maiores serviços à nossa mocidade. Externei, porisso, o desejo de ver fundada aqui tal estabelecimento de ensino a varias pessoas, inclusive ao Dr. Augusto Ribas. Por essa razão, recebo, agora, com o maior prazer a noticia de que um grupo de profissionais diplomados está disposto a levar a iniciativa por diante.

A cerimônia de fundação da faculdade ocorre poucos dias depois, mais precisamente no dia 18 de dezembro de 1936. O local do anúncio foi o salão nobre do mais tradicional educandário de ensino da cidade, o Colégio Regente Feijó.

No dia seguinte ao lançamento o Jornal Diário dos Campos (19 DE DEZEMBRO DE 1936, p. 1) noticia-se:

"A Princeza dos Campos conta com seu primeiro Estabelecimento de Ensino Superior". Tratava-se de um momento histórico:

O dia de hontem terá de figurar em lugar distincto nos anaes educacionaes princezinos, pois que assinala a fundação em nossa cidade do primeiro estabelecimento de ensino superior. Foi fundada, no salão nobre do Gymnasio Regente Feijó, a Escola de Farmacia e Odontologia de Ponta Grossa.

Para esse fim foi levada a effeito importante reunião à qual estiveram presentes: Drs. Augusto Eriksen Ribas, Oscar de Paula Soares, Joaquim de Paula Xavier, Olympio de Paula Xavier, Júlio de Azevedo, Edwaldo Camargo, Rivadavia de Oliveira, Geraldo Brozel, João Casemiro Manzur, José Pinto Rosas, Leopoldo Pinto Rosas, Jayme Gusman, Hermano Jopperet, Epaminondas Novaes Ribas e Haroldo Beltrão.

Foi, então solenemente declarada fundada a Escola de Farmacia e Odontologia de Ponta Grossa. Logo a seguir ficou deliberado que se elegesse a primeira directoria do novel estabelecimento de ensino.

E é assim que Ponta Grossa passa a ter, daqui por diante, o seu primeiro estabelecimento de ensino superior. Oxalá seja elle o primeiro marco para a fundação de nossa Universidade.

Percebe-se pela matéria que a idéia de ampliação do ensino superior na cidade já se encontrava presente na fundação da primeira faculdade.

Pouco tempo depois, o mesmo jornal ratifica a importância da Faculdade de Farmácia e Odontologia de Ponta Grossa para a cidade. Segundo o jornal " Ponta Grossa não progride apenas materialmente, também nos domínios das lettras e das sciencias, vai realizando grandes e promissoras conquistas que, sobremodo, a ilustram. (JORNAL DIÁRIO DOS CAMPOS, 06 DE JANEIRO DE 1937, p. 1).

Na matéria é exaltado, ainda, o apoio incondicional dado pelo Governador Manoel Ribas, que "sem favor algum, tem a visão dos espíritos esclarecidos, a comprehensão da importância da escola e da cultura do povo, não poderia deixar de auxiliar essa iniciativa que, por todos os motivos vem engrandecer e honrar a sua terra natal" (JORNAL DIÁRIO DOS CAMPOS, 06-01-1937, p. 1).

A materialização da criação da faculdade no município deu-se com o anúncio da realização do primeiro vestibular da Faculdade de Farmácia e Odontologia de Ponta Grossa, no jornal Diário dos Campos que enfatizava também que "a installação da Escola de Farmacia e Odontologia em Ponta Grossa, representa, pois, uma etapa a mais na senda 
do progresso das lettras e das sciencias" (JORNAL DIÁRIO DOS CAMPOS, 06 DE JANEIRO DE 1937, p. 6).

Entre os membros do que há pouco chamamos de "elite" local, encontravam-se profissionais da área farmacêutica, médica e odontológica, como os Doutores Joaquim de Paula Xavier e José Pinto Rosas. Esses profissionais, que inicialmente atuaram de forma política para concretização da faculdade, depois da fundação passaram a fazer parte do corpo docente e diretivo da Instituição.

$\mathrm{Na}$ verdade, pode-se observar que era muito restrito o número de profissionais com formação superior na cidade de Ponta Grossa e região. Em meados da década de 30, por exemplo, "existiam seis dentistas com formação superior e um número semelhante de práticos" (Declarante 5), o que representava ser impensável um corpo docente formado com profissionais detentores de uma formação adequada para o funcionamento de uma instituição de ensino superior.

Com o vestibular realizado no dia 15 de março de 1937, a diretoria já constituída da faculdade divulga a relação dos candidatos aprovados ${ }^{9}$ e realiza uma cerimônia destacando o acontecimento.

Este ato, por si só, revela inegavelmente uma transformação na estrutura educacional ponta-grossense, pois a partir deste momento a cidade passaria a contar com todos os níveis de ensino. O jornal Diário dos Campos (16 de MARÇO DE 1937, p.1) registra este fato com a manchete:

Officialmente fundada a Escola de Farmacia e Odontologia do Paraná”

O dia de hontem deverá ficar assignalado em caracteres disteinctos nos annais do ensino da cidade: marcara a installação official da Escola de Farmacia e Odontologia de Ponta Grossa.

A hora 20 numas das salas do Gymanasio Regente Feijó, onde funcionara o novel estabelecimento de ensino superior, teve lugar a cerimonia. [...]

E, assim, esta officialmente fundada e em funcionamento a nossa Escola de Farmacia marco auspicioso que P. Grossa firma no seu evoluir educacional.

Paraná Vieira, em estudos realizados sobre a Universidade Estadual de Ponta Grossa, traz uma visão panorâmica desse cenário ao fazer a seguinte manifestação:

A vocação do povo ponta-grossense para enriquecer o seu patrimônio cultural conquistando o nível universitário, data de quase meio século, pois foi em 1936 que por iniciativa do prefeito Albary Guimarães, liderando um grupo de pessoas gradas, como total apoio do interventor Manoel Ribas, criou-se a Faculdade de Farmácia e Odontologia de Ponta Grossa.

Contando com todo equipamento necessário para os cursos de Farmácia e Odontologia, adquiridos de uma Escola de interior de São Paulo, que encerrava suas atividades, a Faculdade de Farmácia e Odontologia, a primeira do interior, foi instalada no edifício $\mathrm{n}^{\circ} 47$, da praça Marechal Floriano Peixoto. (JORNAL CAMPOS GERAIS, 20 DE JULHO DE 1990, n. 158, p. 1)

Apesar de todo o entusiasmo inicial e da articulação das forças municipais existentes em torno da Faculdade de Farmácia e Odontologia de Ponta Grossa, antes 
mesmo da formação da sua primeira turma, acabou sendo fechada já no primeiro semestre de 1939, com o indeferimento do processo de reconhecimento pelo Conselho Nacional de Ensino $^{10}$. Ruiu-se assim o tão acalentado sonho da sociedade ponta-grossense de contar com uma unidade de ensino superior.

$\mathrm{Na}$ documentação pesquisada, encontramos duas respostas para o fato. A primeira é a de que o fechamento ocorreu por problemas de ordem técnica. A outra explicação encontrada é a de que a Faculdade de Farmácia e Odontologia de Ponta Grossa foi fechada por influência direta da Universidade Federal do Paraná.

Quanto à primeira razão, no parecer do Conselho Nacional de Ensino, o motivo alegado pelos Inspetores foi a do descumprimento de formalidades legais necessárias ao seu funcionamento.

Baseada na imposição dos Inspetores Federais, a Congregação da Faculdade tomou a iniciativa de cancelar as matrículas de seus alunos através da Portaria $n^{\circ} 26$ de 22 de junho de $1939^{11}$.

De acordo com declarante 1, esses problemas efetivamente existiam. Vejamos alguns trechos de sua entrevista que permitem clarificar o mencionado:

Foi instituída em 1936 com o início das atividades em 37. Então a escola funcionou no ano inteiro de 37, no ano inteiro de 38 e em meados de 39 houve assim, após a verificação por uma comissão competente para saber se podia ela ser instituída dentro das normas regimentais, ser reconhecida no futuro. Houve já uma situação diferente, que não havia possibilidade nenhuma que essa escola fosse reconhecida em virtude de que o início da mesma, o alicerce dessa fundação, dessa escola, já estava comprometido. Comprometido por quê? Porque os alunos, os então acadêmicos tinham sido aceitos, é claro, talvez fosse feito assim um vestibular num "cumpadresco" e foram então incluídos com alunos que não tinham completado o segundo grau.

Então também incluíram alunos que possuíam continham o magistério, as chamadas escolas normais que formavam professores, aí também o alicerce estava fraco. $\mathrm{E}$ as condições técnicas também foram comprometidas. $\mathrm{O}$ corpo docente não se comprometeu muito, porque foi também escolhido gente como os médicos da época, farmacêuticos da época, dentistas da época, todos eles com gabarito capaz de corresponder também na época à maneira de se formar um corpo docente. [...] Eram excelentes pessoas, mas não preenchiam aqueles quesitos iniciais para que a escola tivesse condições de ser reconhecida. Então a escola pecou por isso. E ela, em virtude de não ter possibilidade de ser reconhecida, parou porque os seus alunos o que iam fazer?

A maioria deles, como eu também, ao mesmo tempo que estava tirando aqueles dois anos que completavam o segundo grau, também se matriculou, na continuação desses dois anos, no ginásio. Então fez paralelo em 37 que começou, a maioria deles fez o primeiro ano do pré, de complementação do ginásio e o primeiro ano da escola de Farmácia e Odontologia, o segundo ano do pré e o segundo da Farmácia e Odontologia e, quando passou para o terceiro, ano em que nós tínhamos completado o ginásio, é que nós perdemos. Na realidade nós perdemos um ano, o de 39 e não três, porque se nós parássemos em 36 e ficássemos só na escola de Farmácia e Odontologia nós tínhamos perdido nove anos. Então aqueles alunos, aqueles acadêmicos que estavam no ano de 39 
completando o seu curso pararam em junho e se prepararam para fazer exame vestibular em Curitiba. $\mathrm{E}$ os alunos não tiveram o direito que eles pretendiam, de ser encaixados pura e simplesmente, transferidos para a escola em Curitiba. Eles tentaram, mas não foi reconhecido, em virtude da disparidade de situações.

Em outras palavras, a Faculdade de Farmácia e Odontologia de Ponta Grossa não dispunha de instalações adequadas, de um corpo docente dentro das exigências estabelecidas pelo Conselho Nacional de Ensino e, além disso, o primeiro vestibular realizado foi irregular e acabaram sendo matriculados alunos sem a formação exigida para se cursar o ensino superior. Os argumentos são mais do que razoáveis para sustentar a tese de que não havia condições mínimas para a sua continuidade.

A segunda razão aludida para o não funcionamento da faculdade foi a pressão da Universidade Federal do Paraná. Para os defensores dessa tese, a força política e econômica demonstrada para a abertura da faculdade faltou para impedir seu fechamento.

Para o declarante 2,

Naquele tempo a procura pelas Universidades não era como hoje, ela havia um interesse muito grande da Capital avançar, e marcar nome no contexto brasileiro e de ser uma Universidade atuante, significativa. Então o que eles faziam, eles percorriam todo o interior, nos períodos de férias, visitando escolas e buscando adesões para justamente encaminhar os estudantes para a Capital do Estado. E nós fomos vítimas dessa situação. E nós já estávamos em 1937, nós já estávamos no mês de setembro do último ano quando o golpe veio e o interventor federal que era naquela época Manoel Ribas, e então decretou o fechamento dela.

Direção semelhante é tomada pelo declarante 3, que diferentemente do declarante 1 , considerava que o funcionamento da escola era satisfatório. Para este declarante o que faltou foi:

peso político de Ponta Grossa quando daquele episódio que resultou no fechamento daquela escola. Ela fechou por pressão muito grande de Curitiba. Infelizmente a Universidade Federal que naquele tempo era Universidade do Paraná pressionou o Governo para que a autorização de funcionamento da escola fosse caçada. E vários acadêmicos aqui de Ponta Grossa foram concluir seus cursos fora daqui. Ela era uma escola que estava funcionando muito bem, tanto é que eles foram aceitos, alguns em Curitiba e a Dra. Guitil Federmann foi concluir o seu curso de Farmácia no Rio de Janeiro. Foi uma pena, foi uma lástima, mas a responsabilidade maior coube à Universidade do Paraná. Escrevo e assino embaixo.

Mesmo o declarante 1, concordando com o parecer dado pelo Conselho Nacional de Ensino, visualiza que efetivamente ocorreu a interferência citada pelos declarantes 2 e 3. Para o declarante:

desde que começou a funcionar a nossa escola de Odontologia houve reação por parte da Federal. [...] não era uma situação política/administrativa assim de função pública, política pública não, é de concorrência, isso até eu posso admitir, a Universidade do Paraná, porque eles não admitiam que fosse tão fácil criar um curso de Farmácia e Odontologia como foi criado, e nas condições que foi criado e nas 
condições que os acadêmicos eram recebidos condições como nós falamos há pouco irregulares. [...] houve pressão também, mas pressão aonde, na administração pública não, naquele órgão oficial em que eles estavam mais vinculados e entrosados. Ponta Grossa não tinha condições, [...] a influência política de governos não teve influência, se tivesse não teria fechado, o que houve mesmo e eu acredito que houve foi influência da Universidade Federal do Paraná que alertou as autoridades competentes que a escola de Ponta Grossa não estava em condições de sobreviver, e eu até em partes concordo com essa situação.

Paraná Vieira, em relação ao episódio, faz a seguinte declaração:

Os cursos funcionaram até 1939 e, quando da Inspeção Federal para o reconhecimento, os mesmos motivos de ordem técnica impediram esse requisito legal. Os que seriam formados voltaram a cursar mais um ano, na tentativa de regularizar sua situação, mas, infelizmente no ano de 1940, a faculdade encerrou as suas atividades e a maioria dos ex-alunos foram cursar a Universidade Federal do Paraná. (JORNAL CAMPOS GERAIS, 20 DE JULHO DE 1990, n. 158, p. 1)

Outros possíveis "complôs" contra a Faculdade foram levantados. Um deles pelo jornal Diário dos Campos (05 DE JANEIRO DE 1937, p. 1), que publica a seguinte matéria:

[...]. Mal porém se cogita instalar nesta cidade o referido estabelecimento já em Curityba, o sr. Paula Souza, numa entrevista á imprensa tentou prejudicar a instalação deste Curso Superior em Ponta Grossa.

E quais os seus argumentos? Através da sua entrevista, sente-se a intenção de evitar a todo o transe que Ponta Grossa conquiste esta possibilidade, cercear o desenvolvimento cultural deste povo, evitar em síntese que a Princeza dos Campos Gerais venha a possuir uma Escola de Farmácia e Odontologia.

Fala-se nessa entrevista que a Escola seria illegal!

Sandices de preto novo!

Independentemente do motivo, o fato é que a Faculdade de Farmácia e Odontologia de Ponta Grossa encerrou as suas atividades antes, ou melhor, na eminência da formatura da sua primeira turma. Até o final da década de 40, essa tentativa foi a única manifestação do Ensino Superior em Ponta Grossa.

Mais de uma década depois da primeira e frustrante tentativa de criação do nível superior de ensino em Ponta Grossa, uma nova tentativa é efetuada com a criação e implantação da Faculdade Estadual de Filosofia, Ciências e Letras de Ponta Grossa que acaba viabilizando o posterior surgimento de outras faculdades ${ }^{12}$, constituindo assim, efetivamente, o marco do ensino superior em Ponta Grossa.

\section{CONSIDERAÇÕES FINAIS}

O momento que, para fins de apresentação, denominamos de "inicial" reflete uma configuração particular que determinou o nascimento da primeira faculdade de Ponta Grossa. Mais que competência para fazer uma faculdade, os atores de uma forma 
atabalhoada, construíram um sonho e um jogo simbólico que foi se transformando numa peça complexa e sofisticada.

O ensino superior nasceu como não deveria. A estrutura era precária. Não existia um "corpo docente". Os professores, em alguns casos, não tinham formação específica, em outros, sequer tinham formação. Muitos dos alunos "recrutados" não possuíam a formação mínima necessária para cursarem o nível superior de ensino.

Mesmo nascendo dessa forma precária, o que nasceu do sonho da "comunidade" não foi uma faculdade que não deu certo, foi um caminho sem volta: o do ensino superior. O sonho, como vimos, não era de todos, ou, até era. Mas, e isso certamente, muito mais de uns que de outros.

As faculdades eram um instrumento necessário para a produção de mão-de-obra qualificada. Nada mais urgente num Estado em notório desenvolvimento. A condição de segunda cidade do Estado foi fundamental para que Ponta Grossa reivindicasse que a primeira faculdade do interior do Estado viesse para o seu espaço geográfico.

Ao mesmo tempo em que a idéia de universidade trazia no seu âmago a referida funcionalidade, ela, dentro do jogo simbólico do poder, transformava-se em uma oportunidade ímpar para que agentes sociais dotados de uma suposta competência específica alterassem suas posições dentro do espaço público.

Foi com essa lógica que um grupo social, composto por pessoas ligadas à área da saúde, lançou em nome da comunidade ponta-grossense a idéia da Faculdade de Farmácia e Odontologia. A idéia ganhou eco em outros segmentos interdependentes da sociedade. Os agentes engajados no grupo social que desencadeou o movimento dentro dessa configuração assumem os cargos diretivos e as funções de docente na faculdade que surgiu.

A faculdade, apesar do que apresentava de errado, até poderia ter dado certo. A precariedade existente no ensino superior da época poderia até ser uma justificativa. Outra, a de que a condição existente na abertura não era diferente da existente no fechamento. É inegável que esse foi um motivo para o seu fechamento, mas não o único. O principal motivo, sem dúvida, foi a existência de uma força com a qual os agentes sociais engajados não puderam se defrontar: a Universidade Federal do Paraná. A Faculdade de Farmácia e Odontologia de Ponta Grossa era um estorvo para essa Universidade que buscava sua afirmação.

A lição ficou. Pouco mais de uma década se passou até que uma nova unidade de ensino superior fosse implantada, a Faculdade Estadual de Filosofia, Ciências e Letras de Ponta Grossa.

\section{REFERÊNCIAS}

ALMEIDA, José Ricardo Pires de. História da instrução pública no Brasil (1500-1889): São Paulo : Associados, 2008.

BOAVENTURA, Elias. Universidade e estado no Brasil. Piracicaba : Unimep, 1989.

CAMPOS GERAIS - Jornal da Universidade Estadual de Ponta Grossa. Ponta Grossa, 1990.

CUNHA, Luiz Antônio. A universidade temporã. 2. ed. Rio de Janeiro : Francisco Alves, 1986.

D'ARAUJO, Maria Celina. As instituições na era Vargas. Rio de Janeiro : EdUERG,1999. 
Educação \& Sociedade. Campinas: CEDES, v. 29, n. 105, p. 991-1022, 2008.

FACULDADE DE FARMÁCIA E ODONTOLOGIA, Ponta Grossa. Portaria no 26 de 22 de junho de 1939. Livro de Portarias.

Federais - pós-graduação e produtivismo acadêmico. São Paulo: Xamã, 2009.

FRASSON, Antonio Carlos. O ensino superior em Ponta Grossa: o tempo das faculdades. Piracicaba, 2002. 205 f. Tese (Doutorado em Educação) - Programa de PósGraduação em Educação, Universidade Metodista de Piracicaba. 2002.

IPARDES - Fundação Édison Vieira. O Paraná Reinventado: política e governo. Projeto História Política do Paraná, primeiro documento. Curitiba, 1989.

JORNAL DIÁRIO DOS CAMPOS. Ponta Grossa, 1936-1939.

PADIS. Pedro Calil. Formação de uma economia periférica: o caso do Paraná. São Paulo : HUCITEC; Curitiba: Secretária da Cultura e do Esporte do Governo do Estado do Paraná, 1981.

PAIVA, José Maria de. Colonização e catequese. São Paulo: Cortez, 1982.

PARANÁ VIEIRA, Guaracy. UEPG: retrospecto dos 20 anos. Campos Gerais - Jornal da Universidade Estadual de Ponta Grossa. n. 158. 20 jul. 1990.

predomínio privado/mercantil e desafios para a regulação e a formação universitária.

ROSSATO, Ricardo. Universidade : nove séculos e história. Passo Fundo : Edupf, 1998.

SAVIANI, D. História das ideias pedagógicas no Brasil. 2. ed. Campinas: Autores

SCHWARTZMAN, Simon. Tempos de Capanema. São Paulo : Paz e Terra, 2000.

SGUISSARDI, Valdemar. Educação Superior : velhos e novos desafios. São Paulo :

Xamã, 2000.

SGUISSARDI, Valdemar. Modelo de Expansão da Educação Superior no Brasil:

SGUISSARDI, Valdemar. Universidade : Fundação e autoritarismo. São Paulo : Estação Liberdade, 1993.

SGUISSARDI, Valdemar; SILVA JÚNIOR, João dos Reis. Trabalho Intensificado nas

SILVA, Salomão Quadros da. A Era Vargas e a Economia. In. D'ARAÚJO, Maria Celina (org). As instituições brasileiras da era Vargas. Rio de Janeiro : UERJ-FGV, 1999.

TEIXEIRA, Anisio. Educação e universidade. Rio de Janeiro : EdUERG, 1988.

TRINDADE, Hélgio. Universidade em ruínas. Petropólis : Vozes, 1999.

1 Prof. Dr. Antonio Carlos Frasson. Universidade Tecnológica Federal do Paraná - Ponta Grossa. Programa de Pós Graduação em Ensino de Ciência e Tecnologia. e-mail acfrasson@utfpr.edu.br

2 Prof. Dr. Ademir Gebara. Professor Visitante Nacional Sênior da Universidade Federal da Grande Dourados, Faculdade de Educação. Programa de Pós-Graduação em Educação. e-mail ademirgebara@ufgd.edu.br

3 Prof. Dr. Luiz Alberto Pilatti. Universidade Tecnológica Federal do Paraná - Ponta Grossa. Programa de Pós Graduação em Ensino de Ciência e Tecnologia. e-mail - lapilatti@utfpr.edu.br

4 Uma análise mais detalhada desse quadro pode ser consultada em: FRASSON, Antonio Carlos. O ensino superior em Ponta Grossa: o tempo das faculdades. Piracicaba, 2002. $205 \mathrm{f}$. Tese (Doutorado em Educação) - Programa de Pós-Graduação em Educação, Universidade Metodista de Piracicaba.

5 Nos arquivos da Universidade Estadual de Ponta Grossa não existe nenhum material relativo à Faculdade de Farmácia e Odontologia de Ponta Grossa. Os únicos documentos encontrados - 
um livro de portarias, um livro caixa e um livro de inventários - se encontram no Museu dos Campos Gerais. Neles, verificamos a existência de restritos registros.

6 Não localizamos nenhum dos fundadores da Faculdade de Farmácia e Odontologia de Ponta Grossa. Na impossibilidade de trabalharmos com os fundadores, localizamos dois alunos da primeira turma que, posteriormente, atuaram como funcionários/professores nas Faculdades e/ou Universidade Estadual de Ponta Grossa. Outras três entrevistas foram realizadas com funcionários/professores que vivenciaram as faculdades que sucederam a Faculdade de Farmácia e Odontologia de Ponta Grossa. As entrevistas foram codificadas com a denominação declarante e numeradas seqüencialmente. No texto, os entrevistados serão apresentados como sendo do sexo masculino. Com o procedimento garantiu-se o anonimato dos entrevistados.

7 Nos séculos XVIII e XIX, Ponta Grossa era ponto de passagem e de pouso de tropeiros que conduziam as suas tropas entre as cidades de Viamão-RS e Sorocaba-SP.

8 Á frente deste movimento encontravam-se Drs. Paula Soares, Jayme Gusman, Leopoldo Pinto Rosas, Lilian Carrare, Edwaldo Camargo, Hermano Jopperet, Egon Reskamp, Rivadavia de Oliveira e Geraldo Brozel.

9 "EDITAL Chamada para exame vestibular dos cursos de farmacia e odontologia. De ordem do sr. Diretor, deverão comparecer no dia 2 de fevereiro, á rua Dr. Collares $\mathrm{n}^{\circ} 38$, os seguintes alunos inscritos: Farmacia: Arminda Frare, Maria Judita Ditzel, Gervásio Barcellas, José Ramos Reggio, Dalva Borges de Macedo, Guitil Federmann, Egdar Zanoni, Leony Justus, Manoel Rodrigues, Sebastião Ribas Marcondes, Romeu José Woitowich, Edith Justus, Daiana Chapot, Casdidote Mello Jr., Aurora Rodrigues, João Vargas de Oliveira, Nair Mattar, Eudoxia de Paula Xavier, Clodoveu Bittencourt, Paulina Rodrigues Marques, Alfredo Berger, Waldemar N. Santos, Helio Naumann, Pedro Alfredo Ribas, Valdomiro Carneiro dos Santos, Adelino Alves da Silva, Rubens Elke Braga e Isabel Andrade. Odontologia: Neudy de Mattos Guedes, Sebastião Moura, Ottoniel Santos, Othon José do Nascimento, Francisco Barbosa Dimes, Humberto Moacir Schenna, Neuza de Castro Guimarães, Eleonara Amaral de Angelis, José Moskaleski, Adalberto Ribeiro, Alice de Paula Xavier, Alexandre Aracema, Hildegar Oscar Kossatz, Valdevino José Lopes, AltaMiró Baptista de Carvalho, Jair Lopes e Nelson N. Rodrigues". Ibid., 31 jan. 37. p. 6.

10 Atualmente Conselho Nacional de Educação.

11 Portaria $n^{\circ} 26$ de 22 de junho de 1939. Autorizado pela Congregação da Escola, em reuniões de 30 de maio próximo findo, e 21 (22?) do corrente mês, ressalvo cancelar as matriculas de 32 alunos desta Escola, abaixo descriminados, que estão em desacôrdo com as leis de ensino em vigor: Alexandre Aracema, Egdar Zanoni, Hildegar Oscar Kossatz, Humberto Moacir Shena, Jair Lopes, José Hoscalcwski, do $3^{\circ}$ ano do curso de Odontologia; Edipo Ferreira dos Santos Ribas, Nair Mattar, Arminda Frare, Rubens Elhke Braga, Sebastião Ribas Marcondes, Bernando Geerd Screminn, Leony Justus, Dalva Borges de Macedo, Adelino Alves da Silva, Valentim Monteiro Coelho, Ida Sant'Ana e Dino Fecci Colli, do $3^{\circ}$ ano do curso de Farmácia; Chafik Curi, Joaquim de Paula Xavier $F^{\circ}$, Jair Rodrigues Júnior e Aynesio José d'Almeida Becher, do $2^{\circ}$ ano do curso de Odontologia; Emilio Voigt e Florival Fanuchi, do $2^{\circ}$ ano do curso de Farmacia; Adjahyr Basetti, Iracema Moreira, Luiza Luck, Luiz Flávio Araujo, Manoel Pedro dos Santos Lima, do $1^{\circ}$ ano do curso de Odontologia; Minas A. Felippe, Joaquim Braga dos Santos Ribas e Hayde Silveira, do $1^{\circ}$ ano do curso de Farmacia. Ponta Grossa, 22 de junho de 1939. José Pinto Rosas - Diretor. FACULDADE DE FARMÁCIA E ODONTOLOGIA, Ponta Grossa. Portaria n 26 de 22 de junho de 1939. Livro de Portarias.

12 No período ocorreram movimentos para a criação de outras Faculdades; um exemplo é o movimento para criação da Faculdade de Medicina da Escola de Agronomia e Veterinária de Ponta Grossa e de uma Universidade Católica, que acabaram não sendo implantadas.

Recebido: jul-13

Aprovado: $\quad$ abr-14 